\title{
Managing women in pregnancy following bariatric surgery: the midwife as the co-ordinator of care
}

\begin{abstract}
Bariatric surgery is a recommended cost-effective, evidenced-based intervention to reduce weight and associated comorbidities in severely obese people (Gloy et al 2013; Chang et al. 2014). People with a BMI of $40 \mathrm{~kg} / \mathrm{m} 2$ or more or a BMI between $35 \mathrm{~kg} / \mathrm{m} 2$ and $40 \mathrm{~kg} / \mathrm{m} 2$ with other medical conditions such as diabetes, hypertension, high cholesterol and obstructive sleep apnoea meet NICE (2014) criteria to be considered for bariatric surgery. Over the last 10 years in the United Kingdom (UK) surgical interventions (bariatric surgery) have been more widely accessible (NICE, 2014) which in turn means midwives may be required to care for pregnant women who have undergone bariatric surgery such as gastric bands, sleeve gastrectomies and gastic bypasses.

Midwives are required to work co-operatively; recognise and work within the limits of their competence and provide leadership (Nursing and Midwifery Council (NMC), 2018). The aim of this article is to consider the midwife's role as co-ordinator of care for pregnant women who have undergone bariatric surgery. It outlines the most common bariatric procedures and specific considerations including nutritional supplementation required when providing care to women in the antenatal and postnatal periods.
\end{abstract}

Keywords: bariatric surgery; antenatal care; postnatal care; contraception; multi-disciplinary team

\section{Background}

Obesity is graded according to Body Mass Index (BMI) $>35$ and morbid obesity is classified as BMI> 40 (NICE 2014). It is predicted that $48 \%$ of adults will be classified as obese in the United Kingdom (UK) by 2030. Obesity is strongly linked to metabolic diseases (Cardiovascular Disease, Diabetes Mellitus, Non-Alcoholic Fatty Liver Disease, Polycystic Ovary Syndrome (PCOS)) musculoskeletal and respiratory disorders as well as psychological illness; losing weight can improve these co-morbidities. Weight gain can be attributed to many factors such as excessive food intake, sedentary lifestyle, socio-economic deprivation, medications, depression, genetic and endocrine disorders. Several hormonal imbalances affect obesity including ghrelin, which is produced in the fundus of the stomach, androgens and oestrogens. Ghrelin levels increase before eating a meal which leads to hunger. After eating, ghrelin levels reduce which leads to satiety (feeling satisfied). Women with PCOS have low levels of ghrelin which are not affected by eating, therefore causing reduced satiety which results in increased food consumption and weight gain. Androgens increase visceral fat (fat around the organs) and oestrogen is responsible for fat distribution on the hips (subcutaneous) (Whitehead and Bano 2019). 


\section{Risks of obesity in pregnancy}

Almost one in five (20\%) pregnant women have a BMI of 30 or above at the beginning of their pregnancy (Denison et al. 2018). Obese women have an increased risk of miscarriage, hypertension, gestational diabetes, pre-eclampsia and caesarean delivery compared with women of a normal weight. Caesarean sections have associated risks such as infection, bleeding, and other complications which are greater and more complex for an obese woman. Babies born to obese mothers have an increased risk of having birth defects, such as heart and neural tube defects, low birth weights and macrosomia. Therefore losing weight before pregnancy reduces these risks to mother and baby (American College of Obstetricians and Gynaecologists (ACOG), 2009).

In England, the NHS recommends that weight loss is initially supported in the community with lifestyle interventions. If the patient meets the NICE (2014) criteria (see Box 1) the local Clinical Commissioning Group (General Practitioner), who is currently responsible for agreeing funding, can refer the patient to a specialist obesity service led by a multidisciplinary team (MDT).

\section{Box 1}

- Body mass index of $40 \mathrm{~kg} / \mathrm{m} 2$ or more

- Body mass index between $35 \mathrm{~kg} / \mathrm{m} 2$ and $40 \mathrm{~kg} / \mathrm{m} 2$ with other medical conditions such as diabetes, hypertension, high cholesterol and obstructive sleep apnoea

Following engagement with these services, the surgical MDT may consider the patient for bariatric (weight loss) surgery. Bariatric surgery is a recommended cost-effective evidenced-based intervention to reduce weight and associated comorbidities in severely obese people (Gloy et al 2013; Chang et al. 2014).

Within maternity services, many women struggle with fertility for various reasons. Commonly fertility can be affected by obesity and PCOS can be improved with weight loss. In addition, the criteria to be considered for fertility treatment under the National Health Service includes having a $\mathrm{BMI}<30$.

Given this, many women desperate for children resort to weight loss interventions in an effort to lose weight quickly, particularly as age is also a factor associated with infertility (NHS, 2018). To achieve and sustain weight loss people must modify their eating behaviours, increase their exercise and understand why they have struggled with their weight; commonly this is associated with emotions, boredom and trauma and may require psychological support and interventions.

A variety of surgical interventions are available, although successful weight loss following any surgical intervention relies on changing lifestyles including eating behaviours; taking regular exercise and mental wellbeing. However, it is recommended that women do not embark on a pregnancy for 12-18 months post bariatric surgery to ensure the stabilisation of maternal nutrition for the safe 
development of the foetus (Mechanick et al. 2013). If pregnancy occurs before this recommended time frame, close surveillance of maternal weight, nutritional status and ultrasound monitoring of foetal growth should be considered.

Over the last 10 years in the UK surgical interventions have been more widely accessible (NICE, 2014) therefore statistically midwives may have women who have undergone bariatric surgery in their caseload and as a result should have an understanding of their specific care requirements in order to provide them with appropriate individualised care (NMC, 2018).

\section{Common bariatric surgical procedures}

There are several surgical procedures which are commonly used to assist in weight loss using mechanisms such as reducing food intake, altering signals (nerve and hormonal) from the gut, reducing the stomach size and digestion and absorption mainly performed laparoscopically. Ten years ago insertion of the adjustable gastric band was a common procedure being performed both in the NHS and privately. More recently gastric band insertions are declining and currently account for approximately $10 \%$ of operations in the UK. National Bariatric Surgical Register data in 2015-17 reported that Roux-en-Y Gastric bypass surgery is the most common in the UK (45\%) closely followed by $36 \%$ of patients having a sleeve gastrectomy (British Obesity and Metabolic Surgery Society (BOMSS), 2018).

\section{Gastric band}

An inflatable gastric band is placed around the top of the stomach, creating a small pouch. The passage of food through the band stimulates the vagus nerve, which signals the brain to increase feelings of satiety after eating. The band can be adjusted with saline to optimise the feelings of satisfaction. Initial post-operative complications of the gastric band are low, however long-term, a high percentage of patients require removal due to intolerance, slippage, band erosions, port site infections and reflux. Excessive/persistent vomiting can lead to potential nutritional deficiencies and slippage of the gastric band.

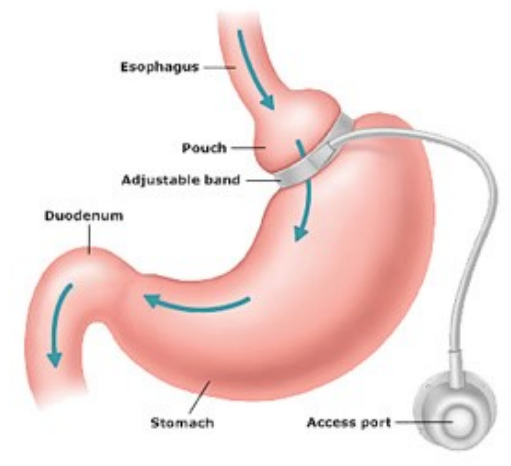

\section{Sleeve gastrectomy}

A sleeve gastrectomy involves removing approximately $80 \%$ of the stomach, thus restricting the volume of food consumed. Additionally, it removes a high 
percentage of the ghrelin hormone which is produced in the fundus of the stomach and suppresses appetite and hunger. Initially, post-operative complications can occur including leaks, ulcers and strictures, and a long-term reflux is common. Vomiting in the early stages can lead to staple line leaks, vomiting later may be associated to strictures, oesophageal dysmotility, and over eating.

Vertical Sleeve Gastrectomy

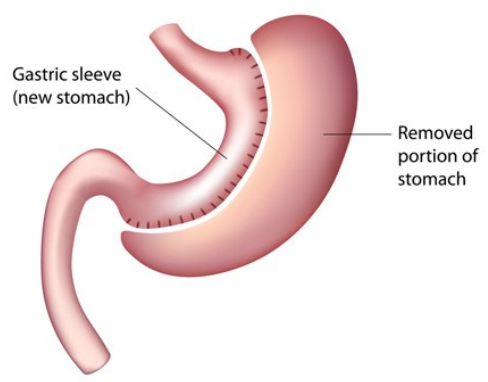

\section{Gastric bypass}

There are various types of gastric bypass being performed such as the mini bypass (One Anastomosis Gastric Bypass) but the Roux-en-Y Gastric bypass remains the most common and has more longterm data. The Roux-en-Y Gastric bypass essentially creates a smaller stomach $(25-30 \mathrm{mls})$ and re-routes the passage of gastric contents bypassing the stomach and proximal small bowel. This re-routing speeds up the transit of gastric contents reducing absorption and therefore nutritional supplementation is required for life following this procedure to prevent deficiencies such as thiamine, iron and Vitamin B12.

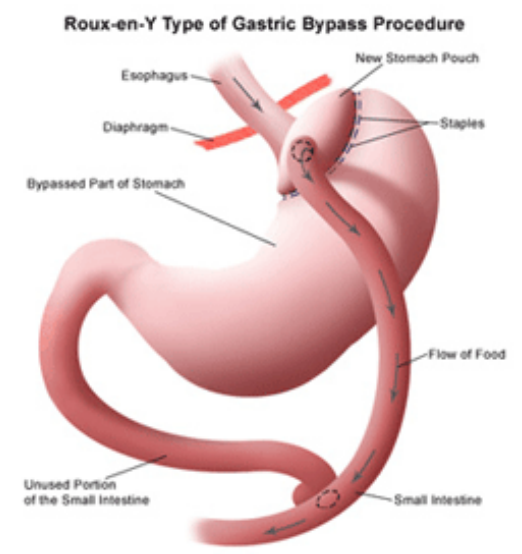

\section{Considerations for antenatal care following bariatric surgery}

\section{Gastric band}

Women who have undergone a gastric band insertion are required to be monitored for symptoms such as difficulty swallowing, vomiting, reflux, recurrent chest infections, night coughs. However, it is important to differentiate whether these symptoms are related to pregnancy or the gastric band. These symptoms are 
commonly related to a tight or slipped gastric band, where deflation should be considered, and the bariatric surgical team consulted. Deflating the gastric band should resolve these symptoms, however, if these symptoms continue, a slipped gastric band should be considered an emergency. A slipped gastric band can be identified using radiology intervention or Oesophago-Gastro-Duodenoscopy (OGD) endoscopy, the choice of identification may depend upon the trimester of the woman's pregnancy. If the gastric band has slipped the bariatric team will remove the gastric band as an emergency procedure. Hyperemesis increases the risk of complications and therefore women with a gastric band should be managed on an individual basis during pregnancy (RCOG, 2018).

\section{Gastric bypass and sleeve gastrectomy}

Women you have undergone a gastric bypass or sleeve gastrectomy may suffer from common pregnancy related problems such as nausea, vomiting, and abdominal pain. However, these symptoms can also mimic postoperative bariatric and gastrointestinal complications and require assessment and investigation by the bariatric surgical team to determine whether the symptoms are related to the surgery, such as internal hernia (gastric bypass), reflux, aspiration and strictures.

Dumping syndrome is more common following a gastric bypass but sometimes occurs following a sleeve gastrectomy, which can occur after eating sugars, highglycaemic carbohydrates and fats. Symptoms include abdominal cramping, bloating, nausea, vomiting, and diarrhoea. Increased levels of insulin and hypoglycaemia can occur later, resulting in tachycardia, palpitations, anxiety, and sweating.

Women who have had a gastric bypass and sleeve gastrectomy surgery are at risk of some oral drugs malabsorption due to a reduction in gastric acid. Therefore slow/modified release preparations are not recommended; oral solutions or rapidrelease preparations are preferred; therefore alternative preparations may need to be considered. It is also imperative that renal function is monitored before prescribing medications, especially if the pregnant woman has suffered from vomiting. When prescribing medications, it is good practice to collaborate with the pharmacist.

As previously discussed the management of symptoms is crucial for women who have had bariatric surgery. To assist midwives in managing women safely and effectively, Table 1 (adapted from BOMSS 2014b) lists common symptoms, potential causes/problems and the recommended action required. 
Table 1: Adapted from BOMSS Emergency Department Management of Bariatric Patients (2014b)

\begin{tabular}{|c|c|c|}
\hline Symptoms & Potential cause/problem & Action \\
\hline $\begin{array}{l}\text { Total dysphagia: } \\
\text { difficulty swallowing saliva, } \\
\text { vomiting } \\
\text { (gastric band) }\end{array}$ & $\begin{array}{l}\text { Acute Band Slippage } \\
\text { (herniation) - Emergency } \\
\text { assessment even if woman } \\
\text { is well }\end{array}$ & $\begin{array}{l}\text { Urgent referral for band } \\
\text { deflation and potential } \\
\text { surgery }\end{array}$ \\
\hline $\begin{array}{l}\text { Gastrointestinal bleed: } \\
\text { vomiting blood, pain, } \\
\text { tachycardia, hypotension }\end{array}$ & $\begin{array}{l}\text { Anastomotic bleed, } \\
\text { potential ulcer }\end{array}$ & $\begin{array}{l}\text { Urgent referral to surgical } \\
\text { team/A\&E for band deflation, } \\
\text { OGD (gastroscopy) } \\
\text { CT scan }\end{array}$ \\
\hline $\begin{array}{l}\text { Intestinal obstruction: } \\
\text { Vomiting, pain }\end{array}$ & $\begin{array}{l}\text { Anastomotic stricture, } \\
\text { internal hernia or port site } \\
\text { hernia }\end{array}$ & $\begin{array}{l}\text { Urgent referral to surgical } \\
\text { team/A\&E }\end{array}$ \\
\hline $\begin{array}{l}\text { Chest pain, tachycardia, } \\
\text { breathlessness }\end{array}$ & $\begin{array}{l}\text { Pulmonary embolus, } \\
\text { myocardial infarction, } \\
\text { gastric pouch problems, } \\
\text { anastomotic leak }\end{array}$ & $\begin{array}{l}\text { CT scan } \\
\text { Urgent referral to surgical } \\
\text { team / A\&E }\end{array}$ \\
\hline Abdominal pain & $\begin{array}{l}\text { Potential obstruction from } \\
\text { internal hernia, anastomotic } \\
\text { leak, constipation, biliary } \\
\text { colic }\end{array}$ & $\begin{array}{l}\text { Referral to surgical team/A\&E } \\
\text { CT scan, OGD (gastroscopy), } \\
\text { USS }\end{array}$ \\
\hline Reflux, no dysphagia of fluids & $\begin{array}{l}\text { Band slip, gastrojejunal } \\
\text { stenosis, oesophageal } \\
\text { dysmotility, hiatus hernia }\end{array}$ & $\begin{array}{l}\text { Refer to bariatric surgical } \\
\text { team, OGD (gastroscopy) }\end{array}$ \\
\hline $\begin{array}{l}\text { Port site infection (Gastric } \\
\text { Band) }\end{array}$ & $\begin{array}{l}\text { Gastric band erosion, } \\
\text { infected band, leaking band }\end{array}$ & $\begin{array}{l}\text { Refer to bariatric surgical } \\
\text { team }\end{array}$ \\
\hline Constipation & $\begin{array}{l}\text { Pre-operative liver } \\
\text { shrinking diet } \\
\text { Post-operative diet (lacks } \\
\text { fibre) }\end{array}$ & $\begin{array}{l}\text { Laxatives, linseed, } \\
\text { vegetables, exercise } \\
\text { depending on pre/post-op } \\
\text { stage }\end{array}$ \\
\hline Diarrhoea & Dumping syndrome & $\begin{array}{l}\text { Reduce carbohydrate and fat } \\
\text { in diet } \\
\text { increase protein and } \\
\text { vegetables }\end{array}$ \\
\hline Hair Loss/thinning & $\begin{array}{l}\text { Lack of protein, selenium, } \\
\text { zinc }\end{array}$ & $\begin{array}{l}60-80 \mathrm{~g} \text { Protein (except if } \\
\text { renal failure). Good quality } \\
\text { Multivitamin }\end{array}$ \\
\hline
\end{tabular}

\section{Nutritional Status Monitoring and Multivitamin requirements and blood tests}

Nutrient deficiencies can also occur in women who have undergone an adjustable gastric band because of decreased food intake or food intolerances.

Pregnancy can aggravate nutritional deficiencies; however, women who have undergone a gastric bypass are at a high risk of micronutrient deficiencies such as vitamin B12, iron, folate and fat-soluble vitamins. Women with previous bariatric 
surgery should have nutritional surveillance and screening for deficiencies during pregnancy. Protein, iron, folate, calcium, and vitamins B12 and D are the most common nutrient deficiencies after gastric bypass surgery and sometimes sleeve gastrectomy. For pregnant women who have had bariatric surgery, screening for micro-nutrient deficiencies should be considered at the beginning of pregnancy and deficiencies should be treated accordingly. A complete blood screen including iron, ferritin, calcium, and vitamin $D$ levels every trimester are recommended (RCOG 2018).

Women planning pregnancy following bariatric surgery are recommended to take $5 \mathrm{mg}$ Folic Acid prior to conception until the 12th week of pregnancy to reduce the risk of neural tube defects (BOMSS 2014a). Additionally, women are advised to take multivitamin and mineral supplements such as Pregnacare, Seven Seas Pregnancy and Centrum Pregnancy Care as they do not contain Vitamin A (retinol). However, women who have had a bypass may require Vitamin $A$ in the beta carotene form but should avoid vitamin and mineral supplementation which contains vitamin $A$ in the retinol form during the first 12 weeks of pregnancy (BOMSS 2014a). For women who have had a gastric bypass, fat soluble vitamins such as Vitamin $A, E$ and $K$ should be monitored due to the limited intake and absorption of fat. Table 2 indicates the nutritional supplements recommended by BOMSS.

Table 2: nutritional supplements in pregnancy (BOMSS 2014a)

\begin{tabular}{|l|l|l|l|}
\hline $\begin{array}{l}\text { Nutritional } \\
\text { supplement }\end{array}$ & $\begin{array}{l}\text { Gastric bypass } \\
\text { (Can affect the } \\
\text { absorption of } \\
\text { Iron, Vitamin B12, } \\
\text { Calcium \& Vitamin } \\
\text { D) }\end{array}$ & $\begin{array}{l}\text { Sleeve } \\
\text { gastrectomy } \\
\text { (Can affect the } \\
\text { absorption of Iron, } \\
\text { Vitamin B12) }\end{array}$ & $\begin{array}{l}\text { Gastric Band } \\
\text { (If too tight a } \\
\text { gastric band this } \\
\text { may affect quality } \\
\text { of diet: protein } \\
\text { and Iron) }\end{array}$ \\
\hline $\begin{array}{l}\text { Multi-vitamin } \\
\text { M/V) }\end{array}$ & Yes & Yes & $\begin{array}{l}\text { Multi-vitamin } \\
\text { (M/V) }\end{array}$ \\
\hline Iron & Yes & Yes & Yes \\
\hline Folate 5mg & Yes & Yes & Yes \\
\hline Vitamin B12 & Yes & Yes & $\begin{array}{l}\text { Multi-vitamin } \\
\text { (M/V) }\end{array}$ \\
\hline $\begin{array}{l}\text { Calcium \& vitamin } \\
\text { D }\end{array}$ & Yes & Yes & $\begin{array}{l}\text { Multi-vitamin } \\
\text { (M/V) }\end{array}$ \\
\hline Selenium & Part of M/V & Part of M/V & $\begin{array}{l}\text { Multi-vitamin } \\
\text { (M/V) }\end{array}$ \\
\hline Zinc \& copper & Part of M/V & Part of M/V & $\begin{array}{l}\text { Multi-vitamin } \\
\text { (M/V) }\end{array}$ \\
\hline
\end{tabular}

\section{Hyperemesis in pregnancy}

Prolonged vomiting such as hyperemesis in pregnancy can lead to severe thiamine deficiency. It is also advisable to assess Vitamin B12 and copper levels and any deficiencies should be corrected (BOMSS 2014a). Occasional regurgitation or 
vomiting of food after bariatric surgery is not uncommon, however prolonged vomiting is not normal and women should be referred back to the bariatric surgical team for further investigation especially if it is felt that it is not pregnancy-related (BOMSS 2014b). For women with gastric bands in situ severe vomiting can cause the gastric band to slip which requires urgent management.

\section{Venous thromboembolism (VTE)}

Women with a BMI $30 \mathrm{~kg} / \mathrm{m} 2$ or greater pre-pregnancy or at booking are at risk of developing VTE during pregnancy and the RCOG guidance GTG No. 37a\&b should be followed.

\section{Contraception after bariatric surgery}

As previously mentioned, it is recommended that pregnancy is delayed for 12-24 months after bariatric surgery due to the initial rapid weight loss. Rapid maternal weight loss in the months after bariatric surgery increases fertility while risks to the foetus from rapid weight loss remain elevated (Saber et al. 2008). Sleeve gastrectomy and gastric bypass operations can affect the absorption of oral medications including contraceptive medication, therefore a change in contraceptive medication or using additional precautions is recommended (Graham et al. 2014).

The Levonorgestrel-releasing Intrauterine device (IUD) has a safe profile (Hillman et al 2011) The hormonal IUDs are highly efficacious, with less pregnancy rates than the copper IUDs (Heinemann et al. 2015) However, IUDs are not always easily inserted and tolerated with reported side effects such as dysmenorrhea, pain, device expulsion, pelvic inflammatory disease and infection (Rowe et al 2016; Steenland 2013).

\section{Conclusion}

Pregnant women who have had bariatric surgery should be regarded as high risk and therefore receive care from the multi-disciplinary team (including, when appropriate, the bariatric surgical team) with the midwife co-ordinating the plan of care (NMC, 2018). Midwives have a responsibility to ensure that women who have had bariatric surgery have a robust clinical assessment including symptoms of vomiting and pain, nutritional status and deficiencies. Communication is recommended between the local bariatric surgical team and bariatric dietitian for expert advice especially if women present with symptoms of excessive vomiting or pain to assess whether their symptoms are pregnancy related or whether pregnancy is masking issues as a result of bariatric surgery.

\section{References}

American College of Obstetricians and Gynecologists (ACOG) (2009) ACOG Practice bulletin: bariatric surgery and pregnancy 105 . Obstetrics and Gynecology 113(6):1405-13 
British Obesity and Metabolic Surgery Society (BOMSS) (2018) Third National Bariatric Surgery Register (NBSR) Report

previewhttp://www.bomss.org.uk/third-nbsr-report-preview/

British Obesity and Metabolic Surgery Society (BOMSS) (2014a) BOMSS Guidelines on peri-operative and postoperative biochemical monitoring and micronutrient replacement for patients undergoing bariatric surgery.

http://www.bomss.org.uk/wp-content/uploads/2014/09/BOMSS-guidelinesFinal-version10ct14.pdf

British Obesity and Metabolic Surgery Society (BOMSS) (2014b) Emergency Department management of bariatric patients. http://www.bomss.org.uk/wpcontent/uploads/2014/04/ED_Poster_Complications_Version_6.pdf

Chang SH, Stoll CR, Song J, et al. (2014) The effectiveness and risks of bariatric surgery: an updated systematic review and meta-analysis, 2003-2012. JAMA Surg 149:275-87.

Denison, FC, Aedla NR, Keag O, Hor K, Reynolds RM, Milne A, Diamond A (2018) Royal College of Obstetricians and Gynaecologists (RCOG) 2018 Green-top Guideline Care of Women with Obesity in Pregnancy Green-top Guideline No. 72 Royal College of Obstetricians and Gynaecologists.

https://doi.org/10.1111/1471-0528.15386

Gloy VL, Briel M, Bhatt DL, et al. (2013) Bariatric surgery versus non-surgical treatment for obesity: a systematic review and meta-analysis of randomised controlled trials. BMJ 347:f5934.

Graham Y, Wilkes, S., Mansour D., Small PK (2014) Contraceptive needs of women following bariatric surgery J Fam Plann Reprod Health Care 40:241-244. doi: $10.1136 /$ jpprhc-2014-100959

Heinemann K, Reed S, Moehner S, Minh TD. (2015) Comparative contraceptive effectiveness of levonorgestrel-releasing and copper intrauterine devices: the European Active Surveillance Study for Intrauterine Devices. Contraception 91:280-283. [PubMed] [Google Scholar]

Hillman JB, Miller RJ, Inge TH (2011) Adolescent menstrual concerns and intrauterine contraception among bariatric surgery patient. J Womens Health 20:533-538. [PMC free article] [PubMed] [Google Scholar]

Khan R, Dawlatly,B, Chappatte, O. (2013) Pregnancy outcome following bariatric surgery. The Obstetrician and Gynaecologist 15:37-43.

Mechanick JI, Youdim A, Jones DB, Garvey WT, Hurley DL, McMahon MM, et al. (2013) Clinical practice guidelines for the perioperative nutritional, metabolic, and nonsurgical support of the bariatric surgery patient-2013 update:

cosponsored by American Association of Clinical Endocrinologists, The Obesity 
Society, and American Society for Metabolic \& Bariatric Surgery. Obesity (Silver Spring) 21 Suppl 1:S1-27.

National Institute for Clinical Excellence (NICE). (2014) Obesity: identification, assessment and management of overweight and obesity in children, young people and adults. Partial update of CG43. London: Department of Health.

National Health Service (NHS) Conditions Infertility [online] (2019) https://www.nhs.uk/conditions/ivf/availability/

NMPA Project Team. National Maternal and Perinatal Audit: Clinical Report 2017. London: RCOG

Nursing and Midwifery Council (NMC) (2018) The Code: Professional standards of practice and behaviour for nurses, midwives and nursing associates. NMC, London

Rowe P, Farley T, Peregoudov A, et al. (2016) Safety and efficacy in parous women of a 52-mg levonorgestrel-medicated intrauterine device: a 7-year randomized comparative study with the TCu380A. Contraception 93:498-506. [PMC free article] [PubMed] [Google Scholar]

Saber AA, Elgamal MH, McLeod MK. (2008) Bariatric surgery: the past, present, and future. Obes Surg 18:121-128. [PubMed] [Google Scholar]

Schlatter J. (2017) Oral Contraceptives after Bariatric Surgery. Obes Facts 10(2):118-126. doi: 10.1159/000449508. Epub 2017 Apr 22. PMID: 28433989

Steenland MW, Zapata LB, Brahmi D, et al. (2013) Appropriate follow up to detect potential adverse events after initiation of select contraceptive methods: a systematic review. Contraception 87:611-624. [PubMed] [Google Scholar]

Whitehead, S, Bano G (2019) Managing Obesity: A practical Guide for Clinicians. Scion Publishing Ltd. Banbury

Authors: Abraham J

Shah N

Power A Senior Lecturer (Midwifery/Faculty Lead for Interprofessional Education, The University of Northampton 